\title{
COVID-19 Infection: Use of Face Masks in Children in Community Settings
}

\section{Sir,}

The coronavirus disease-2019 (COVID-19) pandemic has been reported across all the population groups, with the incidence of the infection being higher among adults and the elderly. The global surveillance reports have shown that as on September 9, 2020, a total of 27486960 cases and 894983 deaths across the affected 216 nations and territories, which amounts to a case fatality rate of $3.2 \% \cdot{ }^{[1]}$ In general, the use of face masks has been advocated along with other risk reduction strategies such as physical distancing, frequent hand hygiene, maintenance of respiratory hygiene, and other strategies like environmental cleaning.

Based on the available estimates, it has been reported that $1 \%-7 \%$ of the confirmed cases are reported among children worldwide, while in the European Union, almost $4 \%$ of the reported cases are in children. ${ }^{[2]}$ It has been observed that most of the diagnosed cases have acquired the infection from the households; however, this could be predominantly because of the fact that schools have been closed in most of the nation as a precautionary measure. ${ }^{[2]}$ The findings of studies have indicated that symptomatic older children have demonstrated higher viral load, and might play a more defining role in the disease transmission in comparison to younger children. ${ }^{[2,3]}$ However, it is unlikely that children can turn out to be the main drivers of COVID-19 transmission. ${ }^{[3]}$

The decision pertaining to the use of masks for children in community settings, in the absence of conclusive evidence, should be taken based on the best interest and the well-being of the child and the feasibility of implementing the same in heterogeneous social and geographical settings. ${ }^{[3,4]}$ It is always advisable to weigh the benefits of wearing masks versus the potential harms (like feasibility or discomfort) of wearing the same. The international welfare agencies have advocated that children in the age-group of $0-5$ years should not wear masks for source control, provided physical distancing, and other infection prevention and control measures are intact. ${ }^{[2,3]}$

However, for children in the 6-11 years age-group, the decision to use a mask should be a risk-based strategy decided based on the transmission pattern in the region, socio-cultural attributes, the ability of the child to strictly comply with the norms prescribed for mask use, the impact of mask-wearing on learning and psychosocial development, and the presence of other factors (like the presence of elderly in home or school going child or disabled child, ventilation, possibility of physical distancing, etc. . ${ }^{[2-4]}$ Moreover, for children aged 12 years and above, the decision for mask use should be derived from the provisions prescribed for adults. ${ }^{[2]}$

The role of age-specific communication with health professionals, parents, teachers or other stakeholders is a must and it should be done predominantly through role modeling. ${ }^{[3]}$ In other words, the role of health communication is vital and it should not only accomplish the desired outcomes but should also be flexible based on the specific needs of the children. ${ }^{[3]}$ Further, we have to pass on the message that the use of masks should not give a false sense of security and it is mandatory to practice the other recommended measures as well. ${ }^{[2,3]}$ The children can be guided about how to use, remove, and dispose a mask. It is essential to ensure easy and free access to mask for children living in low resource settings. ${ }^{[4]}$

Once the public health authorities recommend the use of face masks in community settings, it becomes a must to strengthen the monitoring and evaluation of the practice. This becomes essential as we have to keep a track of the impact of these face masks on the child's health, including mental health and the trends about disease transmission. ${ }^{[2]}$ For those children who are unable to wear face masks due to any reason, the option of using a face shield can be explored, but it is not full-proof as there is a scope of exhalation or inhalation of airborne droplets. ${ }^{[5]}$ At present, the face shield can be looked upon as a tool to prevent the entry of the organism through the eyes. ${ }^{[2]}$

In conclusion, the use of face masks is an effective strategy to reduce the transmission of COVID-19 infection among adults. However, the decision to recommend their use among children should be taken based on the transmission pattern, sociocultural parameters, age of the child and the impact of the use of mask on the health of the child.

\section{Financial support and sponsorship}

Nil.

\section{Conflicts of interest}

There are no conflicts of interest.

Saurabh RamBihariLal Shrivastava, Prateek Saurabh Shrivastava Department of Community Medicine, Shri Sathya Sai Medical College and Research Institute, Sri Balaji Vidyapeeth - Deemed to be University, Chengalpet, Tamil Nadu, India

Address for correspondence: Dr. Saurabh RamBihariLal Shrivastava, Department of Community Medicine, Shri Sathya Sai Medical College and Research Institute, Sri Balaji Vidyapeeth - Deemed to be University, Tiruporur - Guduvancherry Main Road, Ammapettai, Nellikuppam, Chengalpet - 603 108, Tamil Nadu, India. E-mail: drshrishri2008@gmail.com 


\section{RefERENCES}

1. World Health Organization. Weekly Operational Update on COVID-19-9 September 2020; 2020. Available from: https:// www.who.int/docs/default-source/coronaviruse/weekly-updates/ wou-9-september-2020-cleared.pdf?sfvrsn=d39784f7_2. [Last accessed on 2020 Sep 14].

2. World Health Organization. Advice on the use of masks for children in the community in the context of COVID-19. Geneva: WHO Press; 2020. p. 1-6.

3. Ludvigsson JF. Children are unlikely to be the main drivers of the COVID-19 pandemic-A systematic review. Acta Paediatr 2020;109:1525-30.

4. Eikenberry SE, Mancuso M, Iboi E, Phan T, Eikenberry K, Kuang Y, et al. To mask or not to mask: Modeling the potential for face mask use by the general public to curtail the COVID-19 pandemic. Infect Dis Model 2020;5:293-308.

5. Roberge RJ. Face shields for infection control: A review. J Occup Environ Hyg 2016;13:235-42.
This is an open access journal, and articles are distributed under the terms of the Creative Commons Attribution-NonCommercial-ShareAlike 4.0 License, which allows others to remix, tweak, and build upon the work non-commercially, as long as appropriate credit is given and the new creations are licensed under the identical terms.

\begin{tabular}{|l|l|}
\hline \multicolumn{3}{c|}{ Access this article online } \\
\hline Quick Response Code: & Website: \\
\hline & www.ijrc.in \\
\hline
\end{tabular}

How to cite this article: Shrivastava SR, Shrivastava PS. COVID-19 infection: Use of face masks in children in community settings. Indian J Respir Care 2021;10:160-1.

Received: $14-09-2020$ Accepted: 29-09-2020

Revised: $19-12-2020$

Published: $31-01-2021$ 